\title{
Up-regulation of expression of interferon-stimulated gene 15 in the bovine corpus luteum during early pregnancy
}

\author{
L. Yang, ${ }^{*} \dagger$ X. L. Wang, ${ }^{*}$ P. C. Wan, ${ }^{\star}$ L. Y. Zhang,† Y. Wu, ${ }^{*}$ D. W. Tang, ${ }^{*}$ and S. M. Zeng ${ }^{* 1}$ \\ ${ }^{*}$ College of Animal Science and State Key Laboratory for Agrobiotechnology, China Agricultural University, Beijing 100193, China \\ †Department of Animal Science, College of Agriculture, Hebei University of Engineering, Handan 056021, China
}

\begin{abstract}
Interferon- $\tau$ (IFNT), the pregnancy recognition signal in ruminant species, is secreted by conceptus trophectoderm cells and induces expression of IFN-stimulated gene 15 (ISG15) in the uterus and corpus luteum (CL) in ewes. Expression of ISG15 in ovine CL is speculated to be through an endocrine pathway, but it is unclear whether expression of ISG15 in bovine CL is via such a pathway. In this study, CL were obtained from cows on d 16, 25, 60, 120, 180, and 270 of pregnancy, and endometrium, mammary gland, ovarian stroma, and CL were also collected from cows on d 18 of pregnancy and on d 15 and 18 of the estrous cycle. All tissue explants from d 15 of the estrous cycle were cultured in the absence or presence of $100 \mathrm{ng} / \mathrm{mL}$ of recombinant bovine IFNT for $24 \mathrm{~h}$. The results indicated that ISG15 and conjugated proteins were expressed in CL of both cyclic and pregnant cows regardless of pregnancy status and were up-regulated during early pregnancy. The mammary gland from d 18 of pregnancy did not express ISG15, but explants of the mammary gland from d 15 of the estrous cycle did express ISG15 after being treated with IFNT. However, luteal explants from d 15 of the estrous cycle did not express ISG15 after being cultured for $24 \mathrm{~h}$. In conclusion, ISG15 expression is up-regulated in the bovine CL during early pregnancy. Interestingly, cultured CL cells do not respond to IFNT, suggesting that the pregnancy-dependent stimulation of ISG15 expression is controlled by something other than IFNT in the bloodstream.
\end{abstract}

Key words: interferon-stimulated gene 15, corpus luteum, mammary gland, bovine

\section{INTRODUCTION}

Interferon- $\tau$ (IFNT) is a major product of mononuclear trophectoderm cells of ruminant conceptuses during early pregnancy before placental attachment (Roberts, 2007). Its expression is regulated by at least

Received June 30, 2009.

Accepted November 9, 2009.

${ }^{1}$ Corresponding author: zengsm@cau.edu.cn
2 uterine-derived factors, granulocyte-macrophage colony-stimulating factor and fibroblast growth factor 2, as well as multiple signaling pathways (Ealy and Yang, 2009). Its primary action is local to uterine epithelia as a paracrine signal for maternal recognition of pregnancy (Roberts et al., 1992; Bazer et al., 1997). On binding to its specific receptors, uterine epithelia, IFNT directly silences expression of estrogen receptor $\alpha$, and therefore indirectly silences oxytocin receptor expression to prevent pulsatile secretion of $\mathrm{PGF}_{2 \alpha}$ that would otherwise be luteolytic (Bazer et al., 2009). Much of the present data are consistent with this hypothesis in the ovine, but the mechanism is unclear in the bovine (Roberts et al., 2008). Krishnaswamy et al. (2009) recently reported that oxytocin receptor down-regulation was not necessary to reduce the oxytocin-induced uterine release of pulsatile prostaglandin F by IFNT in a bovine endometrial epithelial cell line. This means that other mechanisms may exist in cattle. Arosh et al. (2004) suggested that IFNT directly or indirectly stimulates secretion of prostaglandin $\mathrm{E}_{2}$, which may also participate in the prevention of luteolysis of the corpus luteum (CL) in the bovine.

Interferon- $\tau$ also induces synthesis and secretion of IFN-stimulated genes (ISG) in the uterus, such as ISG 15-kDa protein (ISG15; Johnson et al., 1999), a ubiquitin homolog (ubiquitin cross-reactive protein). In cows and sheep, synthesis of endometrial ISG15 coincides with the secretion of conceptus-derived IFNT (Austin et al., 1996; Johnson et al., 1998). Recently, it was shown that ISG15 is expressed in other tissues during early pregnancy in cattle and sheep. In bovine peripheral blood leukocytes, ISG15 mRNA levels were greater in pregnant cows than in nonpregnant cows on $\mathrm{d}$ 18 and 20 after the onset of estrus (Gifford et al., 2007). Han et al. (2006) also reported that ISG15 mRNA was up-regulated in blood cells from pregnant cows, compared with nonpregnant cows. In the ovine CL, ISG15 mRNA was elevated after intrauterine infusion of or intramuscular or subcutaneous injection with IFNT (Spencer et al., 1999b; Chen et al., 2006). Oliveira et al. (2008) reported that IFNT from the conceptus induces ISG15 expression in peripheral blood cells and in CL 
after being released into the uterine venous system during the period of pregnancy recognition in ewes.

Immune cell populations exist within bovine CL (Lobel and Levy, 1968). Niswender et al. (1997) reported that these immune cells are present primarily as a result of high blood flow to CL. These immune cells may have an active role in controlling the life span and function of the CL, and may have powerful local effects both on luteolysis and on prolonging the functional life span of CL with the assistance of their cytokine products during pregnancy (Mori, 1990; Pate, 2003). Coculturing bovine luteal endothelial cells with peripheral blood mononuclear cells (PBMC) increased monocyte chemoattractant protein 1 secretion by an average of 5 -fold over values for either cell type alone. Luteal endothelial cells cocultured with concanavalin Aactivated PBMC increased monocyte chemoattractant protein 1 secretion by an average of 12-fold compared with controls (Liptak et al., 2005). Fujiwara (2006) suggested that the $\mathrm{PBMC}$ receive several signals from the conceptus and to change their functions, which could, in turn, affect the functions or differentiation of nonimmune organs, such as the CL, during the early stages of pregnancy in humans.

It has been suggested that in sheep, in addition to the intrauterine paracrine actions of IFNT for pregnancy recognition signaling, conceptus-derived IFNT act on CL through an endocrine pathway (Oliveira et al., 2008). Interferon- $\tau$ also activates gene expression in components of the circulating immune system during early pregnancy in ewes (Yankey et al., 2001), but it is unclear whether such a mechanism is responsible for expression of ISG15 in bovine CL. In this study, we hypothesize that bovine conceptus-derived IFNT released into the uterine vein can act on organs other than the uterus, such as the mammary gland and ovary, in the same IFNT environment. If expression of mammary ISG15 is increased in early pregnancy, detection of ISG15 in milk somatic cells would be an ideal noninvasive diagnostic tool for early pregnancy detection. The objectives of the present study were to determine 1) expression of ISG15 in the mammary gland and ovarian stroma during early pregnancy; 2) changes in ISG15 protein expression in CL throughout pregnancy; and 3) effects of recombinant bovine IFNT on ISG15 expression in explant cultures of the mammary gland, ovarian stroma, and CL from nonpregnant cows.

\section{MATERIALS AND METHODS}

\section{Chemicals and Reagents}

All chemicals were purchased from Sigma Chemical Company (St. Louis, MO) unless otherwise stated. All plasticware was from Nunc (Nunc, Nalge Nunc International, Roskilde, Denmark). Mouse anti-bovine ISG15 mAb (5F10) was generously provided by Thomas R. Hansen (Colorado State University, Fort Collins). Recombinant bovine IFNT $\left(1.13 \times 10^{8}\right.$ IU of antiviral activity/mg) was generously provided by R. Michael Roberts (University of Missouri, Columbia). Secondary goat anti-mouse IgG-horseradish peroxidase (IgGHRP; 62-6520, Zymed) and a diaminobenzidine kit were from Invitrogen Corporation (Carlsbad, CA).

\section{Animals and Experimental Design}

Holstein cows between 6 and 8 yr of age were used in all the procedures described. They were managed, including being bred, on the experimental farm of the Institute of Animal Sciences, Chinese Academy of Agricultural Sciences (Beijing, China), and were fed a TMR. Animal care and experimental procedures were approved and conducted under established standards of the Institute of Animal Sciences and Chinese Academy of Agricultural Sciences. Controlled internal drug-releasing devices (InterAg, Hamilton, New Zealand) were used to synchronize estrus, and estrous behavior was monitored 3 times per day. The day of AI was designated d 0 of pregnancy. Cows assigned to the nonpregnant group were not inseminated. The endometrium, mammary gland, ovarian stroma, and CL were sampled from pregnant and nonpregnant cows on d 18 after AI ( $\mathrm{n}=4$ for each group) after slaughter, and these samples were also collected from nonpregnant cows on d 15. Pregnancy was confirmed by the presence of a conceptus in the uterus at slaughter or by the result of pregnancy diagnosis using transrectal ultrasound (d 28 to 30). Corpora lutea were also obtained from cows on d 16, 25, 60, 120, 180, and 270 of pregnancy ( $\mathrm{n}=$ 4 for each group) either at the time of slaughter or by oophorectomy. Some tissues were used for explant cultures, some were fixed in $4 \%$ buffered paraformaldehyde for immunohistochemical analysis, and the remaining tissues were stored at $-80^{\circ} \mathrm{C}$ for protein analysis.

\section{Tissue Explant Culture}

Tissue explants were cultured as described by Austin et al. (1996) with modifications. Briefly, tissue explants of the endometrium, mammary gland, ovarian stroma, and CL from nonpregnant cows on d 15 were placed in sterile PBS solution and immediately transported to the laboratory at room temperature. Tissues were placed in Dulbecco's modified Eagle's medium with F12 salts (DMEM/F12, Gibco BRL, Grand Island, NY) containing penicillin and streptomycin (100 IU/ $\mathrm{mL}, 0.1 \mathrm{mg} / \mathrm{mL}$ ). Approximately $200 \mathrm{mg}$ of each tis- 
sue was minced into small pieces (approximately 2-mm cubes) in a $60-\mathrm{mm}$ culture plate containing $5 \mathrm{~mL}$ of DMEM/F12. The small pieces of endometrium, mammary gland, ovarian stroma, and CL were suspended in a $60-\mathrm{mm}$ culture plate containing $5 \mathrm{~mL}$ of DMEM/ F12 including 10\% fetal bovine serum (Gibco BRL) and were cultured in the absence (control) or presence of $100 \mathrm{ng} / \mathrm{mL}$ of IFNT in an atmosphere of $5 \% \mathrm{CO}_{2}$ in air at $37^{\circ} \mathrm{C}$ for $24 \mathrm{~h}$. The tissues explants were then stored at $-80^{\circ} \mathrm{C}$ for protein analysis.

\section{Immunohistochemical Analysis of Ovaries}

Immunohistochemistry was performed as described by Lucy et al. (1993) for localization of ISG15 expression in the bovine CL and ovarian stroma, with minor modifications. Briefly, cross-sections of ovary, including ovarian stroma and CL, collected from cows on d 16, $18,25,60,120,180$, and 270 of pregnancy and from nonpregnant cows on d 18 were fixed in $4 \%$ paraformaldehyde-PBS at $4^{\circ} \mathrm{C}$ for $24 \mathrm{~h}$. Antigen retrieval was accomplished by microwaving twice for $5 \mathrm{~min}$ in 0.01 $M$ citrate buffer ( $\mathrm{pH} 6.0$ ). The ISG15 and conjugated proteins were localized using $5 \mathrm{~F} 10(1: 10,000)$, but the negative controls were not treated with this antibody. Secondary goat anti-mouse IgG-HRP was used at a dilution of 1:500. The antibody binding sites were visualized by incubating the tissue sections with a diaminobenzidine kit. Small and large luteal cells in bovine CL were identified on the basis of their size and morphology. The large luteal cells were conspicuous by their size, and the more numerous small luteal cells were identified by their morphological features (Rodgers et al., 1986). The immunostaining intensity of the different luteal samples from different cows ( $\mathrm{n}=3$ for each group) was rated by 2 different investigators in a blinded fashion. Large luteal cells and small luteal cells were first analyzed by recording only positive or negative immunoreactivity. Histological subtypes were further analyzed by assigning an immunoreactive intensity of a scale of 0 to 4 , as described previously (Zimmermann et al., 1999). An intensity of $4+$ was given to cells with the highest staining intensity, and an intensity of 0 was assigned to cells with no immunoreactivity.

\section{Western Blot}

Tissues and explants were homogenized at a ratio of $1 \mathrm{~g}$ of tissue or explant per $5 \mathrm{~mL}$ of Laemmli buffer. The protein concentration of the supernatant was determined using a Bradford protein assay (Bio-Rad Laboratories, Hercules, CA) with BSA as the standard. Lysates $(20 \mu \mathrm{g} /$ lane $)$ were separated using $12 \%$ SDSPAGE, followed by transferring proteins to $0.22-\mu \mathrm{m}$ polyvinylidene fluoride membranes (Millipore Corp., Bedford, MA). The polyvinylidene fluoride membranes were blocked in 5\% nonfat milk in Tris-buffered saline plus Tween 20 at $4^{\circ} \mathrm{C}$ overnight. The ISG15 was detected by Western blotting by using $5 \mathrm{~F} 10(1: 100,000)$ and secondary goat anti-mouse IgG-HRP at a 1:2000 dilution. Immunoreactive bands were detected by chemiluminescence using the enhanced chemiluminescence from Amersham Pharmacia Biotech Inc. (Piscataway, NJ). An anti-actin antibody (no. sc-47778, Santa Cruz Biotechnology Inc., Santa Cruz, CA) was used at a dilution of 1:5000 to monitor variation in the loading of samples. Blots were quantified using Quantity One software (version 450, Bio-Rad Laboratories Inc.). Immunoreactive proteins greater than $30 \mathrm{kDa}$ were deemed conjugates (Joyce et al., 2005) and were semiquantified together.

\section{Statistical Analysis}

The data for relative expression of ISG15 and its conjugated proteins were analyzed as a completely randomized design with at least 3 animals per group, using the MIXED procedure models of SAS (version 9.1, SAS Institute Inc., Cary, NC). For CL from different stages of gestation or pregnancy, the model contained the random effect of cow and the fixed effects of stage of gestation, pregnancy status, and the interaction of stage of gestation $\times$ pregnancy status. In addition, for explant cultures, the model contained the random effect of cow and the fixed effects of pregnancy status, treatment, and the interaction of pregnancy status $x$ treatment. The comparisons among the relative expression of different groups were made by using Duncan's multiple range test and by controlling the experimentwise type \pm error equal to 0.05 . Data are presented as least squares means. Differences were considered statistically significant at a $95 \%$ confidence level.

\section{RESULTS}

\section{Expression of ISG15 and Conjugated Proteins in the $C L$}

Both ISG15 and conjugated proteins were present in CL collected on d 18 of the estrous cycle and throughout pregnancy (Figure 1). The relative expression of ISG15 protein in the CL on d 18 of pregnancy was greater $(P<0.05)$ than that from $\mathrm{d} 18$ of the estrous cycle, from d 16 of pregnancy, and after d 25 of pregnancy. Expression of ISG15 protein was lower in CL from nonpregnant cows on d 18 and after d 120 in pregnant cows compared with that from d 16, 25, and 60 of pregnancy $(P<0.05)$. There were no significant 
differences in ISG15 expression among CL from d 16, 25 , and 60 of pregnancy $(P>0.05)$. The expression of ISG15 was not significantly different in CL obtained on d 18 of the estrous cycle and on d 120, 180, and 270 of pregnancy $(P>0.05)$. The conjugated ISG15 proteins in the CL had expression patterns similar to that of free ISG15 (Figure 1).

Immunohistochemistry does not distinguish between ISG15 and conjugated proteins in the tissue sections because the antibody recognizes ISG15, which may or may not exist in the conjugated form. The staining intensity for all luteal samples was $0,1+, 3+, 3+, 2+$, $1+, 1+, 1+$, and $1+$ for control, CL from d 18 of the estrous cycle, and CL from d 16, d 18, d 25, d 60, d 120 , d 180, and d 270 of pregnancy, respectively, where staining intensity was as follows: $0=$ negative; $1+=$ weak; $2+=$ strong; $3+=$ strongest. The staining intensity for ISG15 was the strongest in CL from d 16 and 18 of pregnancy among all the CL evaluated, and the staining for ISG15 was present in the CL on d 18 of nonpregnancy and throughout pregnancy (Figure 2 ). The positive signal for ISG15 was strongly localized in the cytoplasm of large luteal cells, and there was variable staining for ISG15 in small luteal cells (Figure 2, D18P and D25P). It was evident that the immunostaining was limited only to cytoplasm and that staining for ISG15 was weak in ovarian stroma on d 18 of pregnancy, but no staining for ISG15 was detected in ovarian stroma from cows on d 16,25, 60, 120, 180, and 270 of pregnancy or on d 18 of the estrous cycle.

\section{Expression of ISG15 and Conjugated Proteins in the Mammary Gland from $d 18$ of Pregnancy, from the Estrous Cycle, and from Explants Stimulated by IFNT}

Neither ISG15 nor conjugated proteins were expressed in the mammary gland from d 18 of pregnancy, from the estrous cycle, or from explants of mammary gland without IFNT stimuli (Figure 3). Both ISG15 and conjugated proteins were clearly present in the explants of mammary glands cultured in DMEM/F12 with $100 \mathrm{ng} /$ $\mathrm{mL}$ of IFNT for $24 \mathrm{~h}$.

\section{Expression of ISG15 and Conjugated Proteins in the Endometrium and CL from d 18 of the Estrous Cycle and from Their Explants Stimulated by IFNT}

As illustrated in Figure 4, ISG15 proteins were highly expressed in the endometrium from d 18 of pregnancy, but not from d 18 of the estrous cycle. However, weak expression of ISG15 proteins was detected in CL from cows on 18 of the estrous cycle. Endometrial explants from d 15 of the estrous cycle that were cultured with
DMEM/F12 containing $100 \mathrm{ng} / \mathrm{mL}$ of IFNT for $24 \mathrm{~h}$ had more ISG15 proteins than control endometrial explants $(P<0.05)$. However, explants of CL from d 15 of the estrous cycle did not express ISG15 after being cultured in DMEM/F12 with or without $100 \mathrm{ng} / \mathrm{mL}$ of IFNT for $24 \mathrm{~h}$ (Figure 4).

\section{Expression of ISG15 and Conjugated Proteins in Ovarian Stroma from d 18 of Pregnancy, from the Estrous Cycle, and from Explants Cultured with IFNT}

The ovarian stroma on d 18 of pregnancy exhibited weak expression of ISG15 (Figure 5), but the ovarian stroma from d 18 of the estrous cycle did not express ISG15 based on immunohistochemical analysis (Figure 2, D18P and D18N). Supplementation of culture medium with $100 \mathrm{ng} / \mathrm{mL}$ of IFNT for $24 \mathrm{~h}$ increased $(P<$ $0.05)$ both ISG15 and conjugated proteins in cultured explants of ovarian stroma from d 15 of the estrous cycle (Figure 5). The abundance of ISG15 protein stimulated by IFNT in ovarian stroma from d 15 of the estrous cycle was greater than that in ovarian stroma from $d$ 18 of pregnancy.

\section{DISCUSSION}

Interferon- $\tau$, the pregnancy recognition hormone in ruminants, is produced by mononuclear trophectoderm cells of conceptuses at a critical time to prevent regression of CL function. Its major effect has been reported to be limited to within the uterine lumen because it is not detectable in the peripheral circulation of ewes (Bazer and Roberts, 1983). In more recent studies, infusion of exogenous IFNT, via indwelling catheters into the uterine lumen or systemically by subcutaneous or intramuscular injections, extended the CL life span in nonpregnant ewes and cows (Spencer et al., 1999a; Ealy et al., 2006). Arosh et al. (2004) reported that intrauterine infusion of IFNT increased synthesis of prostaglandin $\mathrm{E}_{2}$ without altering synthesis of prostaglandin $\mathrm{F}$ in bovine CL. The CL of ewes express abundant ISG15 mRNA and protein during early pregnancy or after intrauterine infusion or intramuscular injection of IFNT (Spencer et al., 1999b; Chen et al., 2006; Oliveira et al., 2008). Oliveira et al. (2008) speculated that expression of ISG15 in CL was induced by conceptus-derived IFNT released into the uterine veins during the time of maternal recognition of pregnancy in ewes.

Results of our present study revealed that ISG15 and conjugated proteins were present in nonpregnant bovine CL, and their levels increased dramatically from d 16 to 18 of pregnancy and then decreased from d 25 to 60 of pregnancy. Furthermore, there was no significant difference in the levels of ISG15 and conjugated 
proteins after d 60 of pregnancy (Figure 1). These findings are similar to previous results in ewes, except that expression of ISG15 was not detected in ewe CL during midpregnancy or in nonpregnant ewes (Oliveira et al., 2008). It was obvious that the expressions of ISG15 and conjugated proteins in CL were relevant to conceptus IFNT during early pregnancy in cows. Embryonic loss rates were high from d 17 to 19 of gestation, and they decreased from d 28 to 60 of gestation for lactating dairy cows, with no significant decrease after d 60 of gestation (Lucy, 2001), which was consistent with the expression pattern of ISG15, suggesting that embryonic loss during bovine early pregnancy may be due to the insufficient expression of ISG15 and conjugated proteins in CL.

Our results indicated that ISG15 was expressed weakly in ovarian stroma cells, but there was no expression in the mammary gland on d 18 of pregnancy. Inter-
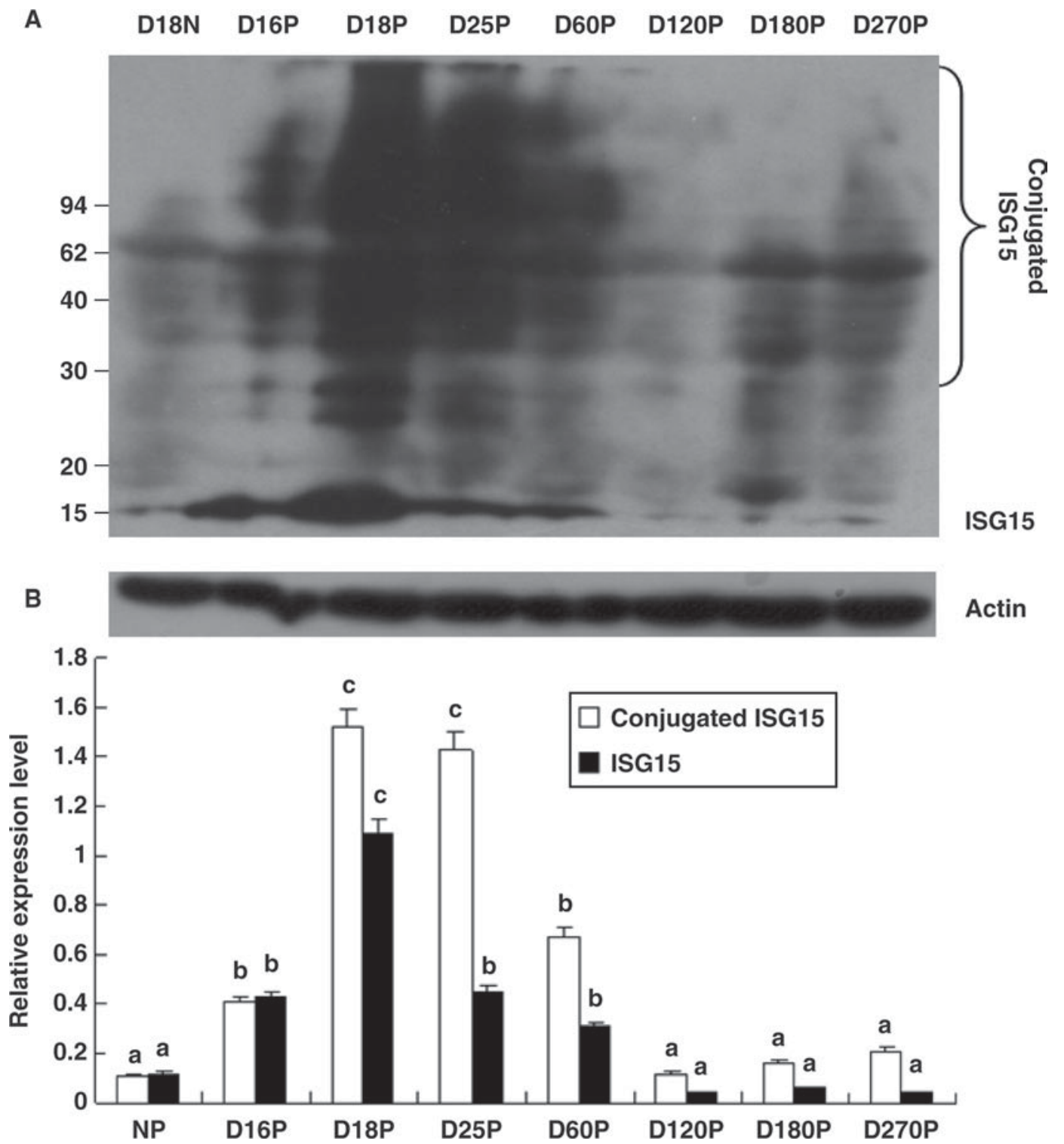

Figure 1. Expression of IFN-stimulated gene 15 (ISG15) protein and its conjugated proteins in bovine corpora lutea (CL) collected on d 18 of the estrous cycle and on d 16, 18, 25, 60, 120, 180, and 270 of pregnancy. Protein extracts (100 $\mu \mathrm{g} /$ lane) were analyzed by Western blotting using a specific anti-ISG15 antibody (panel A). Data $(\mathrm{n}=4)$ are summarized in panel B. All data represent relative values of expression of ISG15 and conjugated proteins compared with actin. Positions of prestained molecular weight standards $\left(\times 10^{3}\right)$ are indicated. Immunoreactive proteins greater than $30 \mathrm{kDa}$ were deemed conjugates and were semiquantified together. Significant differences $(P<0.05)$ are indicated by different letters within columns of the same color. NP $=$ CL from d 18 of the estrous cycle; D18N $=$ CL from d 18 of the estrous cycle; D16P $=$ CL from $d$ 16 of pregnancy; D18P = CL from d 18 of pregnancy; D25P = CL from d 25 of pregnancy; D60P = CL from d 60 of pregnancy; D120P = CL from d 120 of pregnancy; D180P = CL from d 180 of pregnancy; D270P $=$ CL from d 270 of pregnancy. 

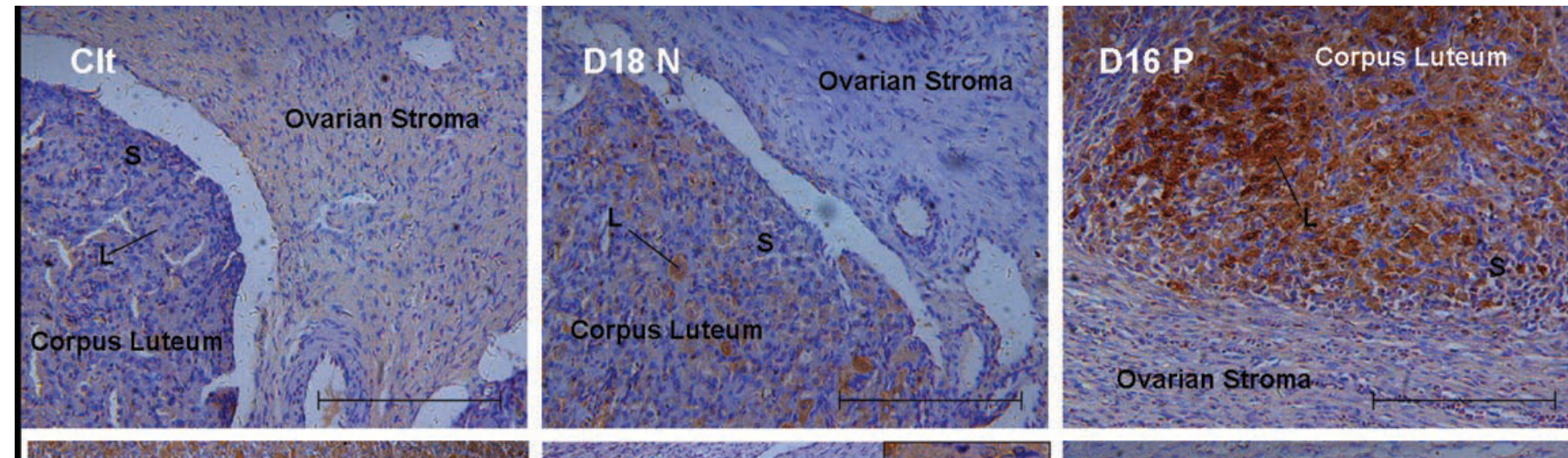

D18 $\mathrm{s}$ Corpus Luteum $(\mathrm{Y})$
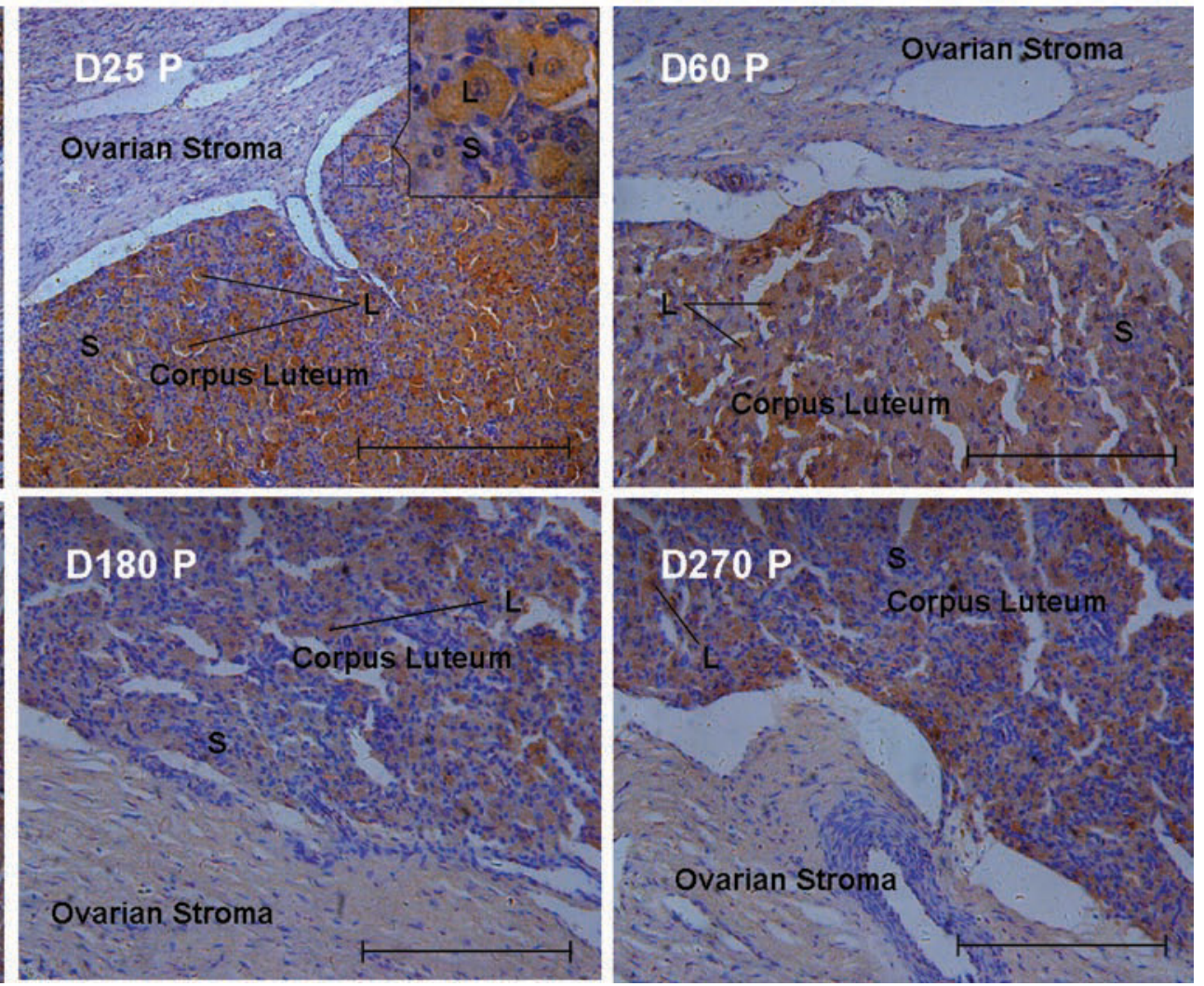

Figure 2. Representative immunohistochemical localization (100× magnification) of IFN-stimulated gene 15 (ISG15) in bovine corpora lutea (CL) collected on d 18 of the estrous cycle and d 16,18,25,60,120,180, and 270 of pregnancy. The large luteal cells were conspicuous by their size, and the more numerous small luteal cells were identified by their morphological features. Immunohistochemistry does not distinguish between ISG15 and conjugated proteins in tissue sections. Clt = control; D18N $=$ CL from $\mathrm{d} 18$ of the estrous cycle; D16P = CL from d 16 of pregnancy; D18P = CL from d 18 of pregnancy; D25P = CL from d 25 of pregnancy; D60P = CL from d 60 of pregnancy; D120P = CL from d 120 of pregnancy; D180P = CL from d 180 of pregnancy; D270P = CL from d 270 of pregnancy; $\mathrm{L}=$ large luteal cells; $\mathrm{S}=$ small luteal cells. Bar $=100 \mu \mathrm{m}$. Color version available in the online PDF. 
A MP MN

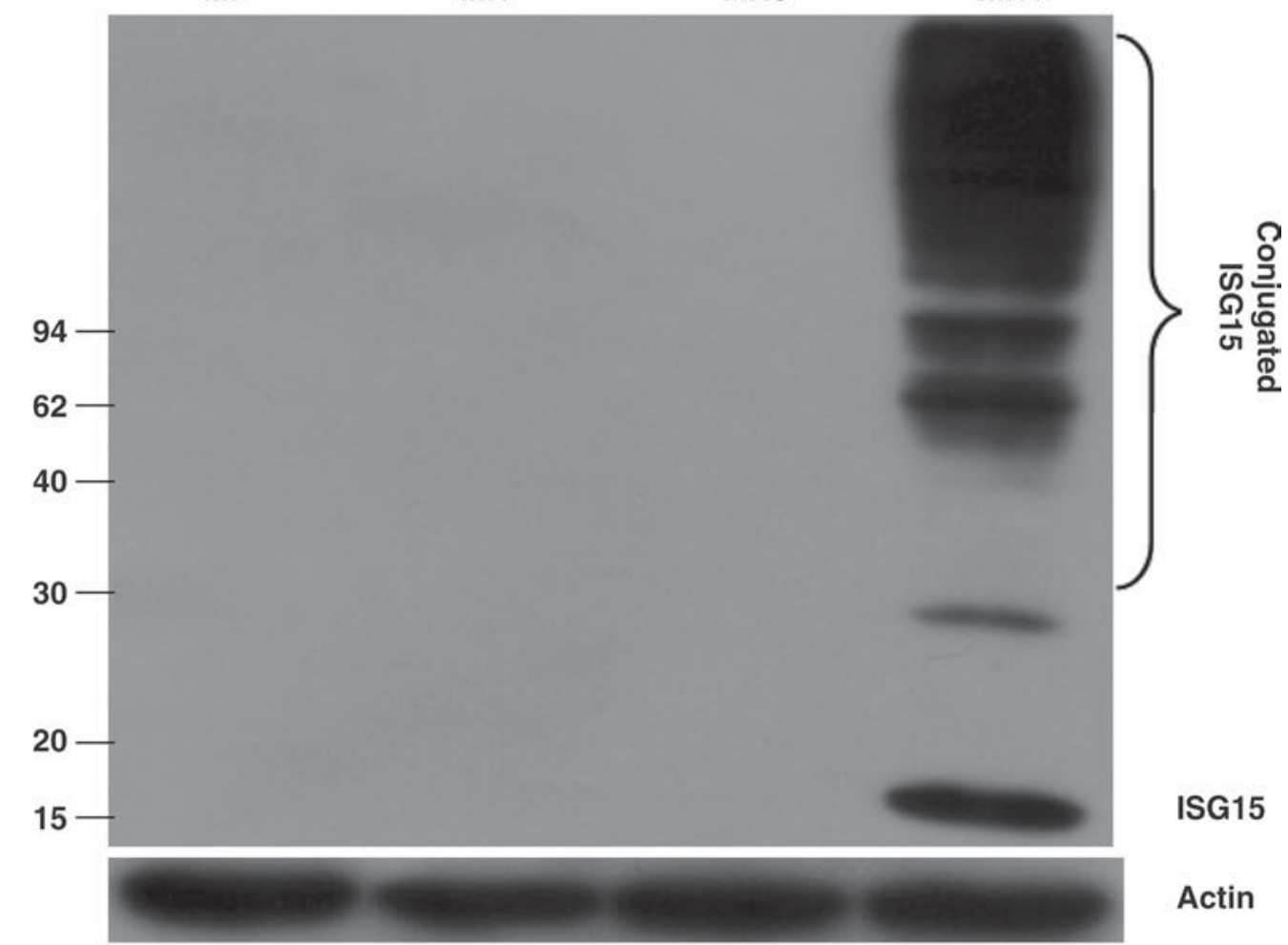

B

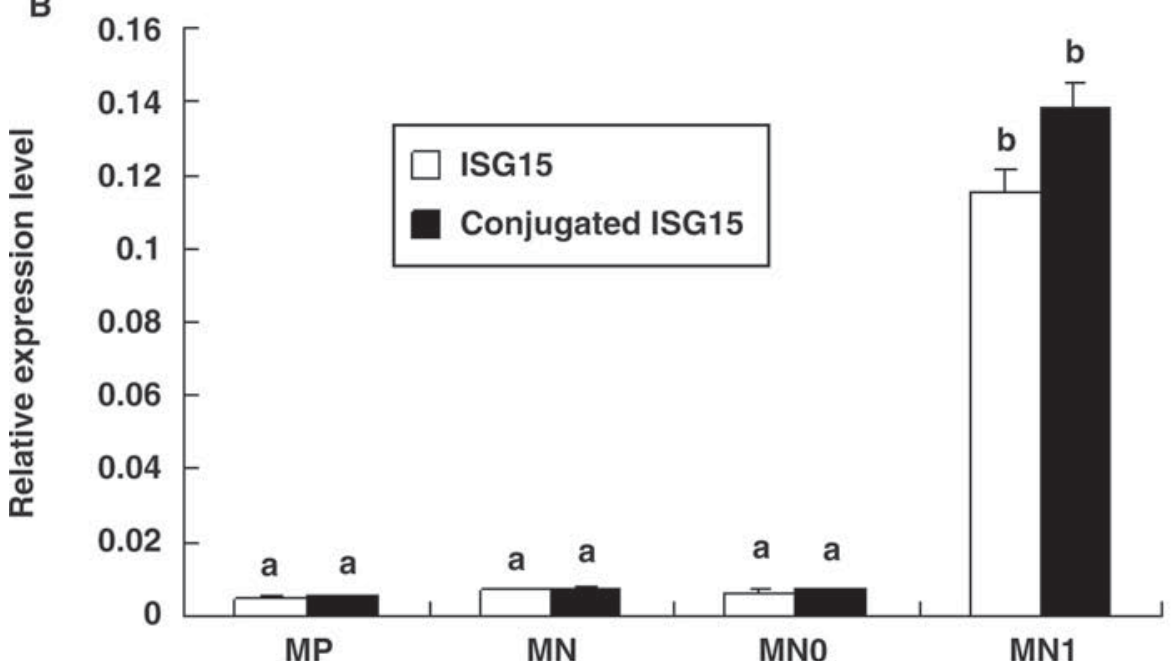

Figure 3. Expression of IFN-stimulated gene 15 (ISG15) in the bovine mammary gland and its explants cultured with or without IFN- $\tau$ (IFNT). Protein extracts (100 $\mathrm{\mu g} /$ lane) were analyzed by Western blotting with a specific anti-ISG15 antibody (panel A). Data (n = 4) summarized in panel B represent relative values of expression of ISG15 and conjugated proteins compared with actin. Positions of prestained molecular weight standards $\left(\times 10^{3}\right)$ are indicated. Immunoreactive proteins greater than $30 \mathrm{kDa}$ were deemed conjugates and were semiquantified together. Significant differences $(P<0.05)$ are indicated by different letters within columns of the same color. MP $=$ mammary gland from d 18 of pregnancy; $\mathrm{MN}=$ mammary gland from d 18 of the estrous cycle; MN0 = explants of the mammary gland from d 15 of the estrous cycle cultured without IFNT for $24 \mathrm{~h}$; MN1 = explants of the mammary gland from d 15 of the estrous cycle cultured with $100 \mathrm{ng} / \mathrm{mL}$ of IFNT for $24 \mathrm{~h}$.

estingly, explants of mammary glands, ovarian stroma, and endometria were capable of expressing ISG15 and conjugated proteins if stimulated by IFNT (Figures 3, 4 , and 5) at concentrations similar to those used in a previous study (Johnson et al., 1999). A dose-response study confirmed that it was a reasonable concentration, at $100 \mathrm{ng} / \mathrm{mL}$ of IFNT (our unpublished data), and the behavior of bovine endometrial and human mam- 
A

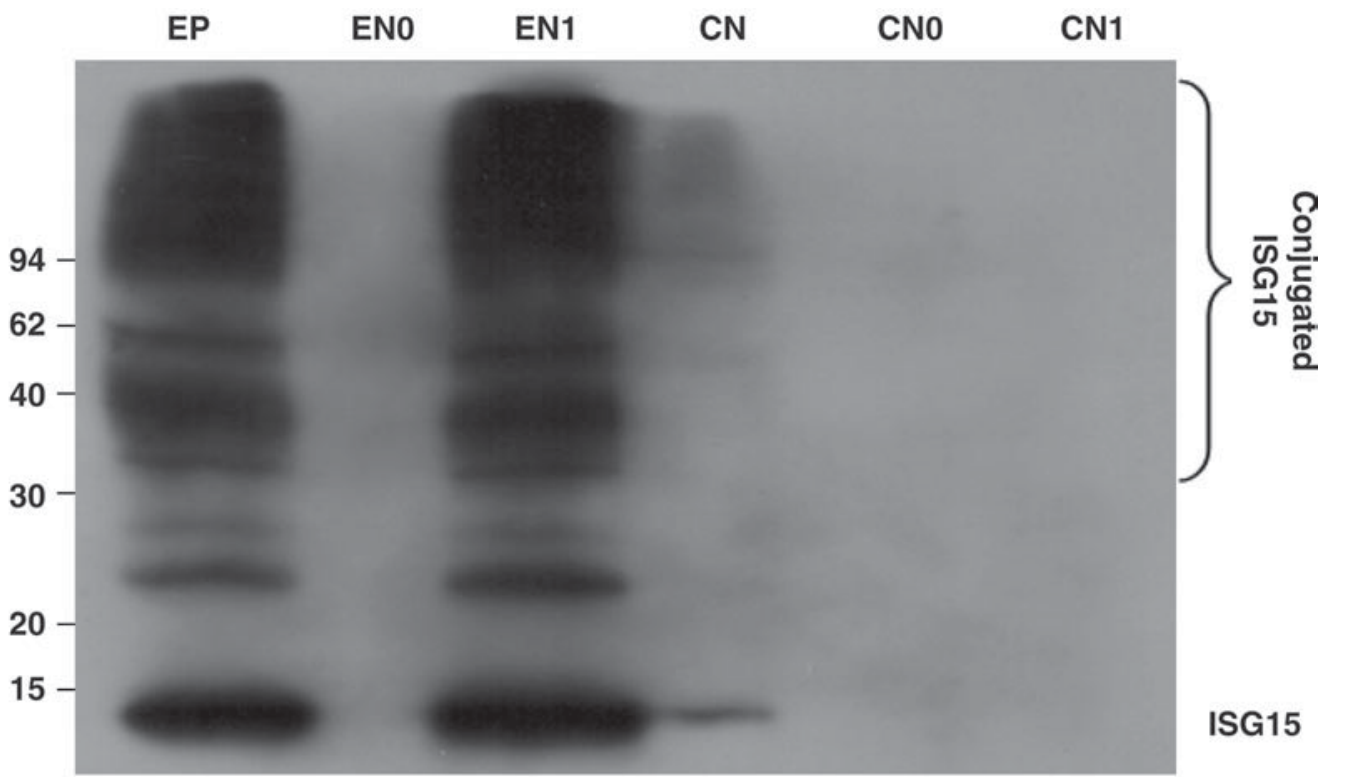

Actin

\section{B}

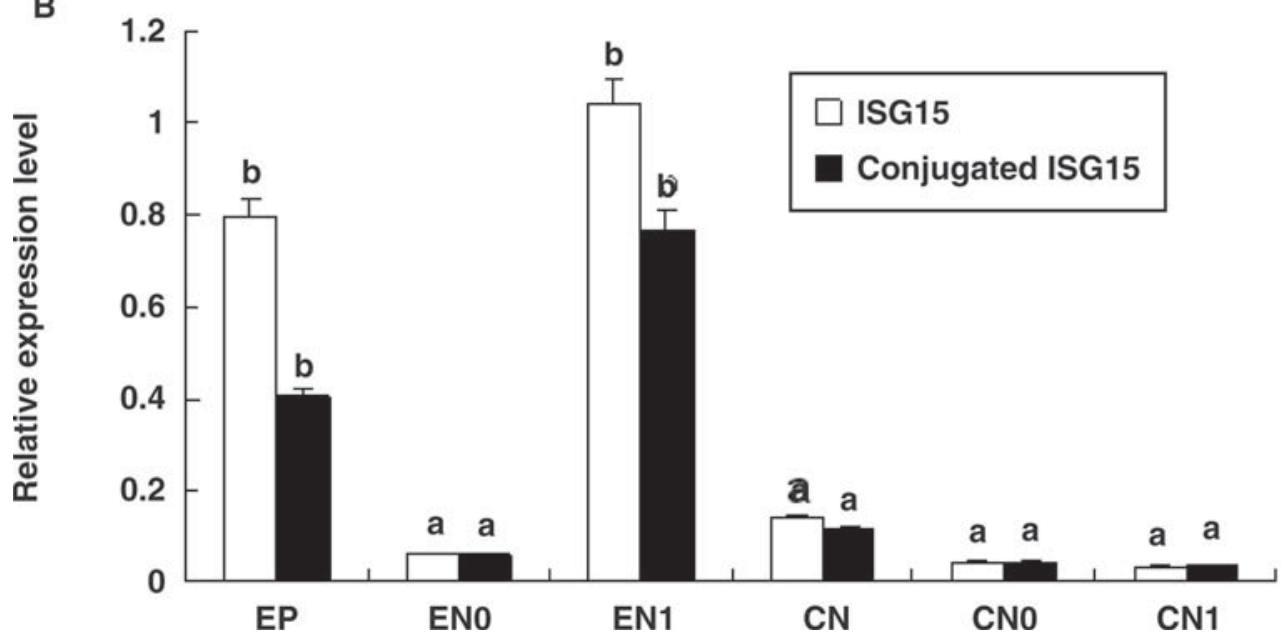

Figure 4. Expression of IFN-stimulated gene 15 (ISG15) in the bovine endometrium and corpus luteum (CL), and their explants cultured with or without IFN- $\tau$ (IFNT). Protein extracts $(100 \mu \mathrm{g} /$ lane) were analyzed by Western blotting with a specific anti-ISG15 antibody (panel A). Data $(\mathrm{n}=4)$ are summarized in panel B. All data represent the relative expression level of ISG15 and conjugated proteins compared with actin. Positions of prestained molecular weight standards $\left(\times 10^{3}\right)$ are indicated. Immunoreactive proteins greater than $30 \mathrm{kDa}$ were deemed conjugates and were semiquantified together. Significant differences $(P<0.05)$ are indicated by different letters within columns of the same color. EP $=$ endometrium from d 18 of pregnancy; EN0 = explants of endometrium from d 15 of the estrous cycle cultured without IFNT for 24 h; EN1 = explants of endometrium from d 15 of the estrous cycle cultured with $100 \mathrm{ng} / \mathrm{mL}$ of recombinant bovine IFNT for $24 \mathrm{~h}$; CN = CL from d 18 of the estrous cycle; $\mathrm{CN} 0=$ explants of CL from d 15 of the estrous cycle cultured without IFNT for $24 \mathrm{~h}$; CN1 = explants of CL from d 15 of the estrous cycle stimulated by $100 \mathrm{ng} / \mathrm{mL}$ of IFNT for $24 \mathrm{~h}$.

mary tissue explants cultured in vitro after at least $24 \mathrm{~h}$ could reflect the metabolic state in vivo before excision (Hillman et al., 1983; Bartol et al., 1985). Normally, the mammary glands in vivo exposed to the same IFNT environment as CL do not express ISG15, but they did express ISG15 in response to IFNT. Therefore, we speculated that conceptus-derived IFNT might act on CL through other pathways rather than the endocrine pathway to stimulate ISG15 expression in bovine CL during early pregnancy.

It is well known that the delivery of prostaglandin $\mathrm{F}$ to $\mathrm{CL}$ is via a countercurrent exchange from the uterine 
vein to the ovarian artery in sheep (McCracken et al., 1972). A few studies have shown that IFN-stimulated genes, such as ISG15, are up-regulated in cells of the uterus as deep as the myometrium during early pregnancy in cows and ewes (Johnson et al., 1998, 1999), but we also found that the mesenterium between the uterine horn containing the conceptus and its ipsilateral ovary on d 18 of pregnancy in bovines did not express ISG15 (data not shown). It seems that IFNT may not cross the uterine vein to the ovarian artery by countercurrent

A
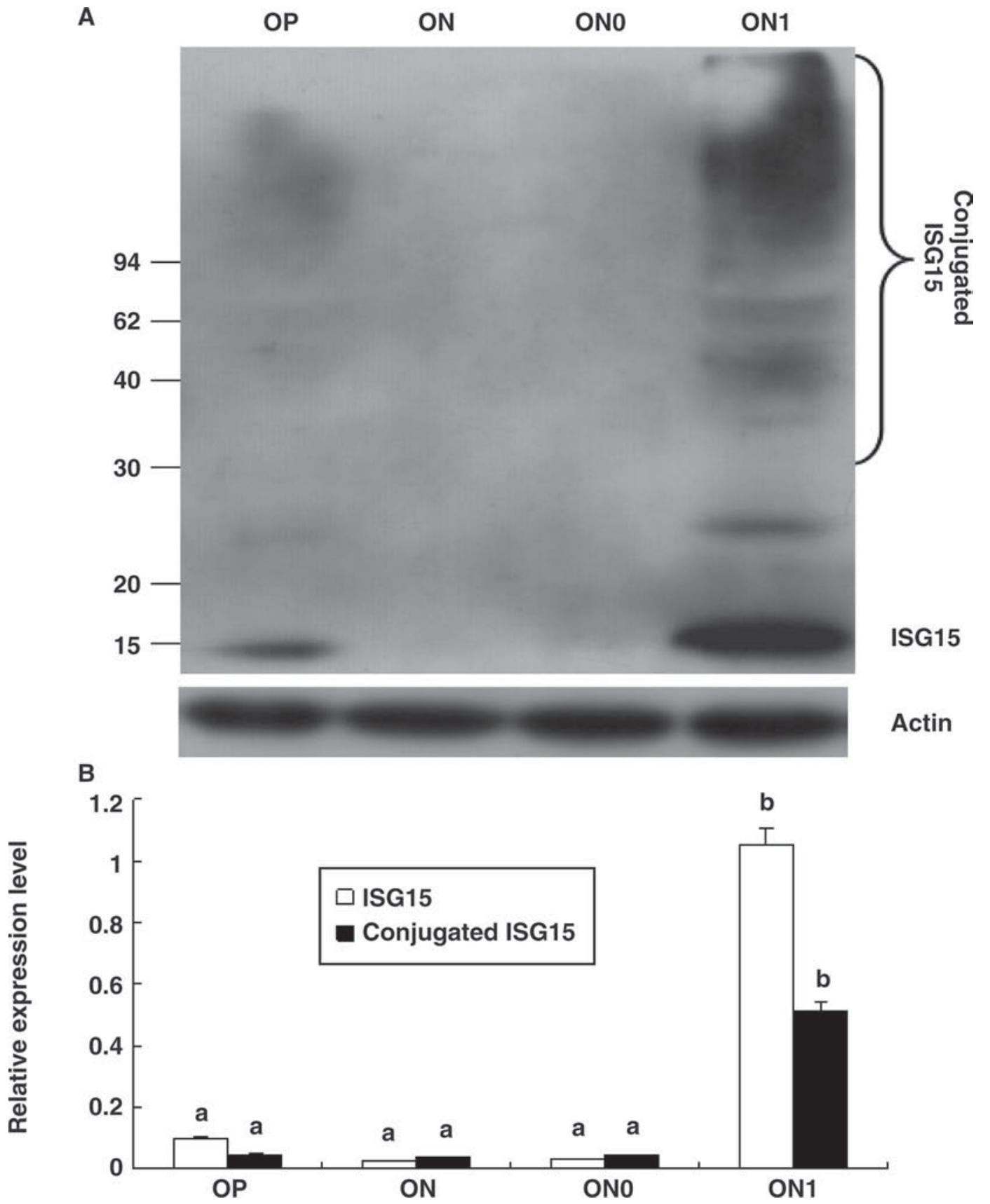

Figure 5. Expression of IFN-stimulated gene 15 (ISG15) in the bovine ovarian stroma and its explants cultured with or without IFN- $\tau$ (IFNT). Protein extracts $(100 \mu \mathrm{g} /$ lane) were analyzed by Western blotting with a specific anti-ISG15 antibody (panel A). Data (n = 4) are summarized in panel B as relative values of expression of ISG15 and conjugated proteins compared with actin. Positions of prestained molecular weight standards $\left(\times 10^{3}\right)$ are indicated. Immunoreactive proteins greater than $30 \mathrm{kDa}$ were deemed conjugates and were semiquantified together. Significant differences $(P<0.05)$ are indicated by different letters within columns of the same color. OP $=$ ovarian stroma from d 18 of pregnancy; $\mathrm{ON}=$ ovarian stroma from d 18 of the estrous cycle; ON0 = explants of ovarian stroma from d 15 of the estrous cycle cultured without IFNT for $24 \mathrm{~h}$; ON1 = explants of ovarian stroma from d 15 of the estrous cycle cultured with $100 \mathrm{ng} / \mathrm{mL}$ of IFNT for $24 \mathrm{~h}$. 
exchange. Similarly, Oliveira et al. (2008) reported that the concentration of bioactive IFNT in uterine venous blood was higher than in uterine arterial blood on $\mathrm{d}$ 15 of pregnancy in ewes, but levels of ISG15 mRNA expressed in lymph nodes from the uterus (mesenteric) were not different from that in lymph nodes from the head (submandibular) on d 15 of pregnancy in ovines. This indicated that IFNT might not be transported to the CL through countercurrent exchange via the mesenterium.

Cross-talk between the embryo and mother is mediated by immune cells, such as PBMC, during early pregnancy in humans (Fujiwara, 2006). Intrauterine administration of autologous PBMC derived from pregnant women may improve live births, pregnancy, and implantation rates (Fujiwara, 2009). The PBMC derived from women in early pregnancy are also known to promote production of progesterone by luteal cells from pregnant and nonpregnant women in vitro (Hashii et al., 1998). Liptak et al. (2005) reported that activated immune cells from PBMC produced factors such as IFN- $\gamma$ (IFNG), which affects progesterone production by bovine luteal cells.

We found that conjugated ISG15 proteins in CL were most abundant in bovine CL on d 18 of pregnancy (Figure 1), and ISG15 mRNA has been reported to be up-regulated in peripheral blood leukocytes and blood cells in pregnant cows during early pregnancy (Han et al., 2006; Gifford et al., 2007). As a ubiquitin cross-reactive protein, ISG15 contains 2 domains with structural homology similar to ubiquitin (Narasimhan et al., 2005). It can bind its target proteins covalently to regulate their function, as well as affect their half-life, subcellular localization, enzymatic activity, and ability to interact with protein or DNA partners (Dye and Schulman, 2007). Thus, functions of CL and PBMC from cows during early pregnancy may be changed because of IFNT-induced expression of ISG15.

The ISG15 was able to stimulate secretion of IFNG by PBMC (D'Cunha et al., 1996), and IFNG stimulated the macrophages to produce IFN- $\beta$ (Gessani et al., 1989), which further induced expression of ISG15 in human and bovine cells (Korant et al., 1984). We also found that the expression of ISG15 and conjugated proteins was greater in highly vascularized CL than in poorly vascularized CL at the same stage after d 60 of pregnancy (our unpublished results). It suggests that blood flow affects expression of ISG15. We suggest, based on results of the present study, that there may be cross-talk between the conceptus and CL through the immune cells in the blood during pregnancy in cows.

The ISG15 stimulated by type I IFN could be secreted by human PBMC (D'Cunha et al., 1996). The immune cells from PBMC were activated by IFNT in the uterus during early pregnancy, which led to increased expression of ISG15 mRNA in the blood cells of cows (Han et al., 2006), and a systemic modulation in the maternal immune system was caused by IFNT (Bazer et al., 2008), which suggests that high levels of ISG15 in bovine PBMC during early pregnancy may be serving an endocrine function to modulate the maternal immune system. Conversely, the ISG15 secreted by the immune cells from PBMC increased expression of IFNG in these cells. When these PBMC enter CL through the blood circulation, the IFNG will stimulate the secretion of IFN- $\beta$ in macrophages, which can act on CL to induce ISG15 expression. This speculation is very likely to be the case because the mature CL is a most highly vascularized tissue with the highest rate of blood flow. Anatomically, each luteal cell is in direct contact with several capillaries (Stocco et al., 2007), which facilitates stimulation of luteal cells by cytokines derived from PBMC.

Our results revealed that both ISG15 and conjugated proteins were expressed in bovine CL throughout pregnancy (Figures 1 and 2). The expression patterns were different from those of the uterus, which did not express ISG15 during the estrous cycle or at midpregnancy (Austin et al., 2004). D'Cunha et al. (1996) reported that low levels of ISG15, as an extracellular cytokine, were present constitutively in human PBMC, and high molecular weight ISG15 conjugated proteins were also present in PBMC extracts constitutively, which could explain the low expression of ISG15 in CL in nonpregnant cows and in cows after d 60 of gestation in our results. However, ISG15 was expressed in bovine endometria only during early pregnancy (Austin et al., 1996), suggesting that the expression of ISG15 in bovine CL may be regulated by PBMC. Joyce et al. (2005) reported that ISG15 was expressed at the uterine-placental interface throughout pregnancy in ewes, and they hypothesized that it was a key component of that microenvironment. Therefore, we speculated that expression of ISG15 and conjugated proteins in CL may be of importance in maintaining luteal function.

In our experiment, the ISG15 was expressed in CL from nonpregnant cows, but explants of CL from nonpregnant cows did not express ISG15 in vitro, even when the explants were stimulated by IFNT (Figure 4). The CL is a transient tissue because luteolysis can be induced by treating cows with exogenous prostaglandin F, which does not imitate luteal cell death in vitro (Petroff et al., 2001). The explants of CL from pregnant and nonpregnant cows did not express ISG15 after being cultured in vitro for $24 \mathrm{~h}$ (data not shown). Takasaki et al. (2009) also reported that CL blood flow was also a critical factor for luteal function in women, and that functional "cross-talk" occurred between vas- 
cular endothelial cells and steroidogenic luteal cells to control luteal function in bovine ovaries (Acosta and Miyamoto, 2004). It was further demonstrated that the up-regulation of ISG15 in bovine CL in early pregnancy was regulated by some factors other than IFNT in the bloodstream.

In conclusion, ISG15 expression is up-regulated in the bovine CL during early pregnancy. Interestingly, cultured luteal cells do not respond to IFNT, suggesting that the pregnancy-dependent stimulation of ISG15 expression is controlled by something other than IFNT in the bloodstream.

\section{ACKNOWLEDGMENTS}

The authors thank R. Michael Roberts (University of Missouri, Columbia) for providing the recombinant bovine IFNT, Thomas R. Hansen (Colorado State University, Fort Collins) for providing the 5F10, and Zhang Qin (China Agricultural University, Beijing, China) for advice on statistical analysis. We also thank Fuller W. Bazer (Texas A\&M University, College Station) for critiquing and careful editing of this paper and Dongbao Chen (University of California, Irvine) for careful editing of this paper. This study was supported by grants from the Natural Science Foundation of China (Beijing; 30771548) and National Key Technologies R\&D Program (Beijing; 2006BAD04A02).

\section{REFERENCES}

Acosta, T. J., and A. Miyamoto. 2004. Vascular control of ovarian function: Ovulation, corpus luteum formation and regression. Anim. Reprod. Sci. 82-83:127-140.

Arosh, J. A., S. K. Banu, S. Kimmins, P. Chapdelaine, L. A. MacLaren, and M. A. Fortier. 2004. Effect of interferon- $\tau$ on prostaglandin biosynthesis, transport, and signaling at the time of maternal recognition of pregnancy in cattle: Evidence of polycrine actions of prostaglandin $\mathrm{E}_{2}$. Endocrinology 145:5280-5293.

Austin, K. J., A. L. Carr, J. K. Pru, C. E. Hearne, E. L. George, E. L. Belden, and T. R. Hansen. 2004. Localization of ISG15 and conjugated proteins in bovine endometrium using immunohistochemistry and electron microscopy. Endocrinology 145:967-975.

Austin, K. J., S. K. Ward, M. G. Teixeira, V. C. Dean, D. W. Moore, and T. R. Hansen. 1996. Ubiquitin cross-reactive protein is released by the bovine uterus in response to interferon during early pregnancy. Biol. Reprod. 54:600-606.

Bartol, F. F., R. M. Roberts, F. W. Bazer, and W. W. Thatcher. 1985. Characterization of proteins produced in vitro by bovine endometrial explants. Biol. Reprod. 33:745-759.

Bazer, F. W., R. C. Burghardt, G. A. Johnson, T. E. Spencer, and G. Wu. 2008. Interferons and progesterone for establishment and maintenance of pregnancy: Interactions among novel cell signaling pathways. Reprod. Biol. 8:179-211.

Bazer, F. W., and R. M. Roberts. 1983. Biochemical aspects of conceptus-endometrial interactions. J. Exp. Zool. 228:373-383.

Bazer, F. W., T. E. Spencer, and G. A. Johnson. 2009. Interferons and uterine receptivity. Semin. Reprod. Med. 27:90-102.
Bazer, F. W., T. E. Spencer, and T. L. Ott. 1997. Interferon tau: A novel pregnancy recognition signal. Am. J. Reprod. Immunol. $37: 412-420$.

Chen, Y., J. A. Green, E. Antoniou, A. D. Ealy, N. Mathialagan, A. M. Walker, M. P. Avalle, C. S. Rosenfeld, L. B. Hearne, and R. M. Roberts. 2006. Effect of interferon- $\tau$ administration on endometrium of nonpregnant ewes: A comparison with pregnant ewes. Endocrinology 147:2127-2137.

D’Cunha, J., S. Ramanujam, R. J. Wagner, P. L. Witt, E. Knight Jr. and E. C. Borden. 1996. In vitro and in vivo secretion of human ISG15, an IFN-induced immunomodulatory cytokine. J. Immunol. 157:4100-4108.

Dye, B. T., and B. A. Schulman. 2007. Structural mechanisms underlying posttranslational modification by ubiquitin-like proteins. Annu. Rev. Biophys. Biomol. Struct. 36:131-150.

Ealy, A. D., K. A. Pennington, and T. M. Rodina. 2006. Interferon- $\tau$ polymorphisms and their potential functions in ruminants. Annu. Rev. Biomed. Sci. 8:9-18.

Ealy, A. D., and Q. E. Yang. 2009. Control of interferon-tau expression during early pregnancy in ruminants. Am. J. Reprod. Immunol. 61:95-106.

Fujiwara, H. 2006. Immune cells contribute to systemic cross-talk between the embryo and mother during early pregnancy in cooperation with the endocrine system. Reprod. Med. Biol. 5:1929 .

Fujiwara, H. 2009. Do circulating blood cells contribute to maternal tissue remodeling and embryo-maternal cross-talk around the implantation period? Mol. Hum. Reprod. 15:335-343.

Gessani, S., F. Belardelli, A. Pecorelli, P. Puddu, and C. Baglioni. 1989. Bacterial lipopolysaccharide and gamma interferon induce transcription of beta interferon mRNA and interferon secretion in murine macrophages. J. Virol. 63:2785-2789.

Gifford, C. A., K. Racicot, D. S. Clark, K. J. Austin, T. R. Hansen, M. C. Lucy, C. J. Davies, and T. L. Ott. 2007. Regulation of interferonstimulated genes in peripheral blood leukocytes in pregnant and bred, nonpregnant dairy cows. J. Dairy Sci. 90:274-280.

Han, H., K. J. Austin, L. A. Rempel, and T. R. Hansen. 2006. Low blood ISG15 mRNA and progesterone levels are predictive of nonpregnant dairy cows. J. Endocrinol. 191:505-512.

Hashii, K., H. Fujiwara, S. Yoshioka, N. Kataoka, S. Yamada, T. Hirano, T. Mori, S. Fujii, and M. Maeda. 1998. Peripheral blood mononuclear cells stimulate progesterone production by luteal cells derived from pregnant and non-pregnant women: Possible involvement of interleukin-4 and-10 in corpus luteum function and differentiation. Hum. Reprod. 13:2738-2744.

Hillman, E. A., M. G. Valerio, S. A. Halter, L. A. Barrett-Boone, and B. F. Trump. 1983. Long-term explant culture of normal mammary epithelium. Cancer Res. 43:245-257.

Johnson, G. A., K. J. Austin, E. A. Van Kirk, and T. R. Hansen. 1998. Pregnancy and interferon-tau induce conjugation of bovine ubiquitin cross-reactive protein to cytosolic uterine proteins. Biol. Reprod. 58:898-904.

Johnson, G. A., T. E. Spencer, T. R. Hansen, K. J. Austin, R. C. Burghardt, and F. W. Bazer. 1999. Expression of the interferon tau inducible ubiquitin cross-reactive protein in the ovine uterus. Biol. Reprod. 61:312-318.

Joyce, M. M., F. J. White, R. C. Burghardt, J. J. Muñiz, T. E. Spencer, F. W. Bazer, and G. A. Johnson. 2005. Interferon stimulated gene 15 conjugates to endometrial cytosolic proteins and is expressed at the uterine-placental interface throughout pregnancy in sheep. Endocrinology 146:675-684.

Korant, B. D., D. C. Blomstrom, G. J. Jonak, and E. Jr. Knight. 1984. Interferon-induced proteins. Purification and characterization of a 15,000-dalton protein from human and bovine cells induced by interferon. J. Biol. Chem. 259:14835-14839.

Krishnaswamy, N., G. Danyod, P. Chapdelaine, and M. A. Fortier. 2009. Oxytocin receptor down-regulation is not necessary for reducing oxytocin-induced prostaglandin $\mathrm{F}_{2 \alpha}$ accumulation by interferon- $\tau$ in a bovine endometrial epithelial cell line. Endocrinology 150:897-905. 
Liptak, A. R., B. T. Sullivan, L. E. Henkes, M. P. Wijayagunawardane, A. Miyamoto, J. S. Davis, B. R. Rueda, and D. H. Townson. 2005. Cooperative expression of monocyte chemoattractant protein 1 within the bovine corpus luteum: Evidence of immune cellendothelial cell interactions in a coculture system. Biol. Reprod. 72:1169-1176.

Lobel, B. L., and E. Levy. 1968. Enzymic correlates of development, secretory function and regression of follicles and corpora lutea in the bovine ovary. Part II: Formation, development and involution of corpora lutea. Acta Endocrinol. 59:S35-S51.

Lucy, M. C. 2001. Reproductive loss in high-producing dairy cattle: Where will it end? J. Dairy Sci. 84:1277-1293.

Lucy, M. C., R. J. Collier, M. L. Kitchell, J. J. Dibner, S. D. Hauser, and G. G. Krivi. 1993. Immunohistochemical and nucleic acid analysis of somatotropin receptor populations in the bovine ovary. Biol. Reprod. 48:1219-1227.

McCracken, J. A., J. C. Carlson, M. E. Glew, J. R. Goding, D. T. Baird, K. Green, and B. Samuelsson. 1972. Prostaglandin $\mathrm{F}_{2 \alpha}$ identified as a luteolytic hormone in sheep. Nat. New Biol. 238:129-134.

Mori, T. 1990. Immuno-endocrinology of cyclic ovarian function. Am. J. Reprod. Immunol. 24:80-89.

Narasimhan, J., M. Wang, Z. Fu, J. M. Klein, A. L. Haas, and J. J. Kim. 2005. Crystal structure of the interferon-induced ubiquitinlike protein ISG15. J. Biol. Chem. 280:27356-27365.

Niswender, K. D., J. Li, M. R. Powell, K. R. Loos, R. M. Roberts, D. H. Keisler, and M. F. Smith. 1997. Effect of variants of interferon- $\tau$ with mutations near the carboxyl terminus on luteal life span in sheep. Biol. Reprod. 56:214-220.

Oliveira, J. F., L. E. Henkes, R. L. Ashley, S. H. Purcell, N. P. Smirnova, D. N. Veeramachaneni, R. V. Anthony, and T. R. Hansen. 2008. Expression of interferon (IFN)-stimulated genes in extrauterine tissues during early pregnancy in sheep is the consequence of endocrine IFN- $\tau$ release from the uterine vein. Endocrinology 149:1252-1259.

Pate, J. L. 2003. Lives in the balance: Responsiveness of the corpus luteum to uterine and embryonic signals. Reprod. Suppl. 61:207217.

Petroff, M. G., B. K. Petroff, and J. L. Pate. 2001. Mechanisms of cytokine-induced death of cultured bovine luteal cells. Reproduction 121:753-760.
Roberts, R. M. 2007. Interferon-tau, a Type 1 interferon involved in maternal recognition of pregnancy. Cytokine Growth Factor Rev. 18:403-408.

Roberts, R. M., Y. Chen, T. Ezashi, and A. Walker. 2008. Interferons and the maternal-conceptus dialog in mammals. Semin. Cell Dev. Biol. 19:170-177.

Roberts, R. M., J. C. Cross, and D. W. Leaman. 1992. Interferons as hormones of pregnancy. Endocr. Rev. 13:432-452.

Rodgers, R. J., H. F. Rodgers, M. R. Waterman, and E. R. Simpson. 1986. Immunolocalization of cholesterol side-chain-cleavage cytochrome P-450 and ultrastructural studies of bovine corpora lutea. J. Reprod. Fertil. 78:639-652.

Spencer, T. E., C. A. Gray, G. A. Johnson, K. M. Taylor, A. Gertler, E. Gootwine, T. L. Ott, and F. W. Bazer. 1999a. Effects of recombinant ovine interferon tau, placental lactogen, and growth hormone on the ovine uterus. Biol. Reprod. 61:1409-1418.

Spencer, T. E., A. G. Stagg, T. L. Ott, G. A. Johnson, W. S. Ramsey, and F. W. Bazer. 1999b. Differential effects of intrauterine and subcutaneous administration of recombinant ovine interferon on the endometrium of cyclic ewes. Biol. Reprod. 61:464-470.

Stocco, C., C. Telleria, and G. Gibori. 2007. The molecular control of corpus luteum formation, function, and regression. Endocr. Rev. $28: 117-149$

Takasaki, A., H. Tamura, K. Taniguchi, H. Asada, T. Taketani, A. Matsuoka, Y. Yamagata, K. Shimamura, H. Morioka, and N. Sugino. 2009. Luteal blood flow and luteal function. J. Ovarian Res. doi:10.1186/1757-2215-2-1

Yankey, S. J., B. A. Hicks, K. G. Carnahan, A. M. Assiri, S. J. Sinor, K. Kodali, J. N. Stellflug, and T. L. Ott. 2001. Expression of the antiviral protein $\mathrm{Mx}$ in peripheral blood mononuclear cells of pregnant and bred, non-pregnant ewes. J. Endocrinol. 170:R7R11.

Zimmermann, K. C., M. Sarbia, A.-A. Weber, F. Borchard, H. E. Gabbert, and K. Schror. 1999. Cyclooxygenase-2 expression in human esophageal carcinoma. Cancer Res. 59:198-204. 